Published in: Plant Mol. Biol. (2005) 58:295-303

\title{
Relationship between allelic state of T-DNA and DNA methylation of chromosomal integration region in transformed Arabidopsis
}

\section{thaliana plants}

\begin{abstract}
Frédéric G. Masclaux ${ }^{1,2}$, Rafael Pont-Lezica ${ }^{1}$, and Jean-Philippe Galaud ${ }^{1,3}$
${ }^{1}$ Surfaces Cellulaires et Signalisation chez les Végétaux, UMR 5546 CNRS-Université Paul Sabatier, Pôle de Biotechnologie végétale, 24 chemin de Borde-Rouge, BP17, 31326 Castanet-Tolosan, France.

${ }^{2}$ Present adress : Université de Genève, Laboratoire de Génétique végétale, Sciences III 30, Quai Ernest-Ansermet, CH-1211 Genève 4, Switzerland

${ }^{3}$ Author for correspondence: Jean-Philippe Galaud, Surfaces Cellulaires et Signalisation chez les Végétaux, UMR 5546 CNRS-Université Paul Sabatier, Pôle de Biotechnologie végétale, 24 chemin de Borde-Rouge, BP17, 31326 Castanet-Tolosan, France. Phone number: +33 5621935 28; Fax: +33 5621935 02; e-mail: galaud@scsv.ups-tlse.fr
\end{abstract}

\begin{abstract}
T-DNA insertions are currently used as a tool to introduce, or knock out, specific genes. The expression of the inserted gene is frequently haphazard and up to now, it was proposed that transgene expression depends on the site of insertion within the genome, as well as the number of copies of the transgene. In this paper, we show that the allelic state of a T-DNA insertion can be at the origin of epigenetic silencing. A T-DNA insertional mutant was characterized to explore the function of AtBP80a', a vacuolar sorting receptor previously associated with germination. Seeds homozygous for the T-DNA do not germinate, but this can be overcome by a cold treatment and maintained by the following generations. The nongerminating phenotype is only observed in homozygous seed produced by heterozygous plants indicating that it is correlated with the allelic state of the T-DNA in parental lines. Analysis of the region between the T-DNA insertion and the ATG codon of atbp80a' showed that cytosine methylation is highly enhanced in chromatin containing the T-DNA. Data presented here show that an unpaired DNA region during meiosis could be at the origin of a de novo cytosine methylation mechanism.
\end{abstract}

Key-Words: Arabidopsis thaliana; DNA methylation; germination; ploidy level; T-DNA.

Abbreviations: $\mathrm{KAN}^{\mathrm{R}}$, kanamycin resistant; T-DNA, transfer DNA; VSR, Vacuolar Sorting Receptor; WT, wild type. 


\section{Introduction}

Epigenetic silencing causes problems for the agricultural use of transgenic plants, since the silencing of gene expression by a DNA fragment present in excess in the genome has often been reported (Bourque, 1995). However, plants take advantage of the silencing mechanisms to protect their own genome integrity against proliferation of mobile elements such as transposons and viruses (Kumpatla et al., 1998). Epigenetic phenomena are not fully understood, but both methylation of cytosine residues in DNA, and chromatin remodeling appeared to play a key function in epigenetic control in various organisms (Li et al., 2002). These modifications do not alter DNA sequence, but result in changes of DNA accessibility for regulatory proteins (Meyer, 2001). These mechanisms would allow stable propagation of gene activity states from one generation to the next. Knowledge of de novo methylation mechanisms mainly comes from the characterization of transgenic plants. It was reported that transcriptional gene silencing is often associated to DNA methylation and chromatin remodeling (Verbsky et al., 2001; Meyer, 2000; Paszkowski and Whitham, 2001). It can be induced by DNA-DNA pairing mechanism (Vaucheret, 1993) and experimental evidence also indicates that RNA-DNA coupling can also be at the origin of de novo DNA methylation (Wassenegger et al., 1994; Matzke et al., 2001). In mammals, it was observed that DNA lacking a partner during meiosis, such as the $\mathrm{X}$ chromosome in males, could be silenced by histone methylation (Bean et al., 2004) indicating that the genetic imprinting of individual loci or whole chromosomes was established during gametogenesis. In the haploid fungus Neurospora crassa, it was shown that a gene unpaired from its homologue during meiosis, could induce the silencing of all homologous sequences by a process named Meiotic Silencing by Unpaired DNA (MSUD) (Shiu et al., 2001; Shiu and Metzenberg, 2002).

In this work, to explore the function of AtBP80a', a vacuolar sorting receptor from Arabidopsis thaliana previously associated with germination (Cao et al., 2000; Laval et al., 2003), a T-DNA insertional mutant containing a kanamycin resistance gene $\left(\mathrm{KAN}^{\mathrm{R}}\right)$ was used to evaluate the role of AtBP80a' in planta. We show that the T-DNA insertion located in the promoter region of the VSR gene is responsible for seed germination inhibition through an epigenetic mechanism. To gain new insight into epigenetic mechanisms, the atbp $80 a^{\prime}$ mutant was then used as a tool to explore the existence of a relationship between T-DNA ploidy level and DNA methylation.

\section{Materials and methods}

\section{Plant material}

Arabidopsis thaliana ecotype Wassilewskija (Ws-4) was used for the wild type (WT) and the mutant. The atbp80a' $A$. thaliana mutant came from the FLAGdb FST database (http://genoplante-info.infobiogen.fr/FLAGdb) (Samson et al., 2002).

\section{DNA analysis}

Genomic DNA was extracted as reported (Laval et al., 2003). PCR assays performed to evaluate the allelic state of atbp $80 a^{\prime}$ used primers complementary to the left border of the TDNA (Tag5: 5'ctacaaattgccttttcttatcgac3') and sequences located upstream ( $a^{\prime} 1$ : 5'tcacatgcattccatgaatgtg3') or downstream (a'2: 5'ataacgctatcaagccacgtg3') of the T-DNA insertion site (Fig. 1A). 


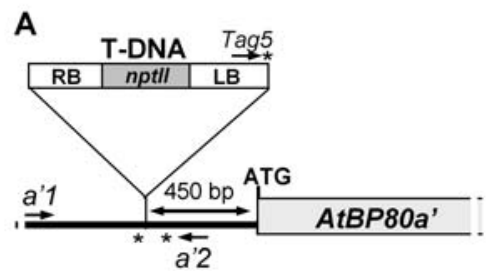

\begin{tabular}{lccc}
\hline B & & & \\
\hline T4 & $\begin{array}{c}\text { Non } \\
\text { germinating } \\
\text { seeds (\%) }\end{array}$ & $\begin{array}{c}\text { Kan } \\
\text { resistant } \\
\text { plants (\%) }\end{array}$ & $\begin{array}{c}\text { Kan } \\
\text { sensitive } \\
\text { plants (\%) }\end{array}$ \\
\hline WT & $2.6 \pm 0.7$ & $0 \pm 0$ & $97.4 \pm 0.7$ \\
\hline T4.1 & $21.4 \pm 0.06$ & $67.9 \pm 0.1$ & $32.5 \pm 1.9$ \\
\hline T4.2 & $29.4 \pm 3.9$ & $69.7 \pm 5.7$ & $30.3 \pm 5.7$ \\
\hline T4.3 & $21.6 \pm 3.4$ & $75.1 \pm 4.4$ & $24.6 \pm 4.2$ \\
\hline T4.4 & $26.1 \pm 2.6$ & $76.3 \pm 1.2$ & $23.6 \pm 1.2$ \\
\hline T4.5 & $29 \pm 1.9$ & $71.2 \pm 2.0$ & $28.7 \pm 2.0$ \\
\hline T4.6 & $22.8 \pm 2.5$ & $73.6 \pm 5.2$ & $26.3 \pm 5.7$ \\
\hline T4.7 & $16.8 \pm 3.0$ & $72.9 \pm 2.7$ & $27 \pm 2.7$ \\
\hline T4.8 & $28.5 \pm 4.1$ & $76.6 \pm 4.2$ & $23.3 \pm 4.2$ \\
\hline T4.9 & $28.9 \pm 4.7$ & $73.4 \pm 3.2$ & $26.5 \pm 3.1$ \\
\hline T4.10 & $25.2 \pm 5.8$ & $78.9 \pm 8.0$ & $20.7 \pm 7.6$ \\
\hline
\end{tabular}

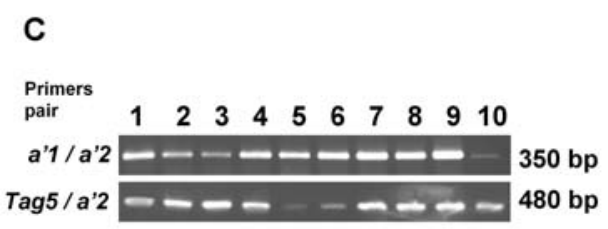

Figure 1. Molecular analyses. (A) Schematic representation of the insertion zone of the T-DNA in the atbp80a' gene. Primers used for the molecular characterization of the mutant lines are indicated by arrows (Tag5; $\left.a^{\prime} 1 ; a^{\prime} 2\right)$. (B) Results of germination tests performed on several lots of T4 seeds (T4.1 to T4.10). Results of germination and of kanamycin-resistant and-sensitive plants are given as percentages of total seed number sowed on MS medium containing a selective agent (kanamycin). Results are the means of three independent experiments. (C) PCR analysis carried-out on DNA extracted from $\mathrm{KAN}^{\mathrm{R}}$ plants with different primer combinations, corresponding either to the T-DNA left border (Tag5) or to regions upstream $\left(a^{\prime} 1\right)$ and downstream $\left(a^{\prime} 2\right)$ of the insertion area.

\section{Viability tests and germination assays}

To estimate embryo viability, integuments from seeds were removed and embryos were incubated in a solution containing $1 \%$ fluorescein diacetate for $30 \mathrm{~min}$, washed in distilled water and observed under fluorescence microscopy at 470$490 \mathrm{~nm}$ excitation. Germination assays were performed using different seed batches. Each of them was sown in triplicate $(80-100$ seeds per Petri dish) on water-soaked filter paper and incubated in a growth chamber $\left(23^{\circ} \mathrm{C}, 16 \mathrm{~h}\right.$ light $)$.

For kanamycin segregation analysis, germination was done on selective medium containing $75 \mu \mathrm{g} / \mathrm{ml}$ kanamycin. Germination was scored every day during a 5-day period after imbibition. For stratification, sown seeds were placed for $48 \mathrm{~h}$ at $4^{\circ} \mathrm{C}$ before transfer to $23^{\circ} \mathrm{C}$.

\section{Mucilage detection and electron microscopy analyses}

Seeds were imbibed for $24 \mathrm{~h}$ in water before being transferred to an aqueous solution of 0.03 $\%(\mathrm{w} / \mathrm{v})$ ruthenium red for mucilage detection at room temperature for $10 \mathrm{~min}$ (Western et al., 2000). They were rinsed with distilled water before observation under stereomicroscope. For scanning electron microscopy, mature dried seeds were coated with gold and examined with an electron microscope (Hitachi C450) at an acceleration voltage of $15 \mathrm{kV}$.

\section{DNA methylation analyses by bisulfite genomic sequencing}

Genomic DNA (500 ng) was mixed with $1 \mu \mathrm{g}$ of salmon sperm DNA and digested at $37^{\circ} \mathrm{C}$ with $X$ ho I before alkaline denaturation with $0.6 \mathrm{M} \mathrm{NaOH}$. The bisulfite method (Grunau et al., 2001) was used. For DNA prepared from atbp80a' mutant, PCR amplification was performed using a primer complementary to the left border of the T-DNA (5'ggtaataggatactgggattcgttttggat3') and a primer anchored to the ATG initiation translation region (5'aaataacacagaaactgcttcatcttcaaa3'). For DNA obtained from WT, PCR was carriedout using a primer located $650 \mathrm{bp}$ upstream of the ATG codon (5'aattaattgttttgttatatggaaagaggt3') and the same primer corresponding to ATG region. PCR products were cloned in pGEM-T and sequenced. 


\section{Results}

\section{Analysis of atbp80a' mutant phenotype}

$\mathrm{T} 3$ seeds corresponding to the mutant were sown on selective medium containing kanamycin to discriminate WT and transformed lines. PCR was performed on DNA from resistant plants, using the primers indicated in Fig. 1A. We found that all the T3 plants analyzed were hemizygous for the transgene. PCR products resulting from Tag5/a'2 primer amplification were sequenced to confirm the T-DNA location 450 nucleotides upstream of the ATG translation initiation codon (Fig. 1A). Southern blotting using a radiolabeled probe corresponding to the complete T-DNA indicated that the genome of the atbp $80 a$ ' mutant contained a single T-DNA insertion as suggested by kanamycin segregation analyses (not shown). Germination assays of T4 seeds on selective medium indicated that $25 \%$ of seeds failed to germinate, $25 \%$ were kanamycin sensitive and $50 \%$ were $\mathrm{KAN}^{\mathrm{R}}$ (Fig 1B). This suggests that $\mathrm{T} 4$ germinating $\mathrm{KAN}^{\mathrm{R}}$ seeds were hemizygous for the T-DNA, as confirmed by PCR analysis (Fig. 1C).

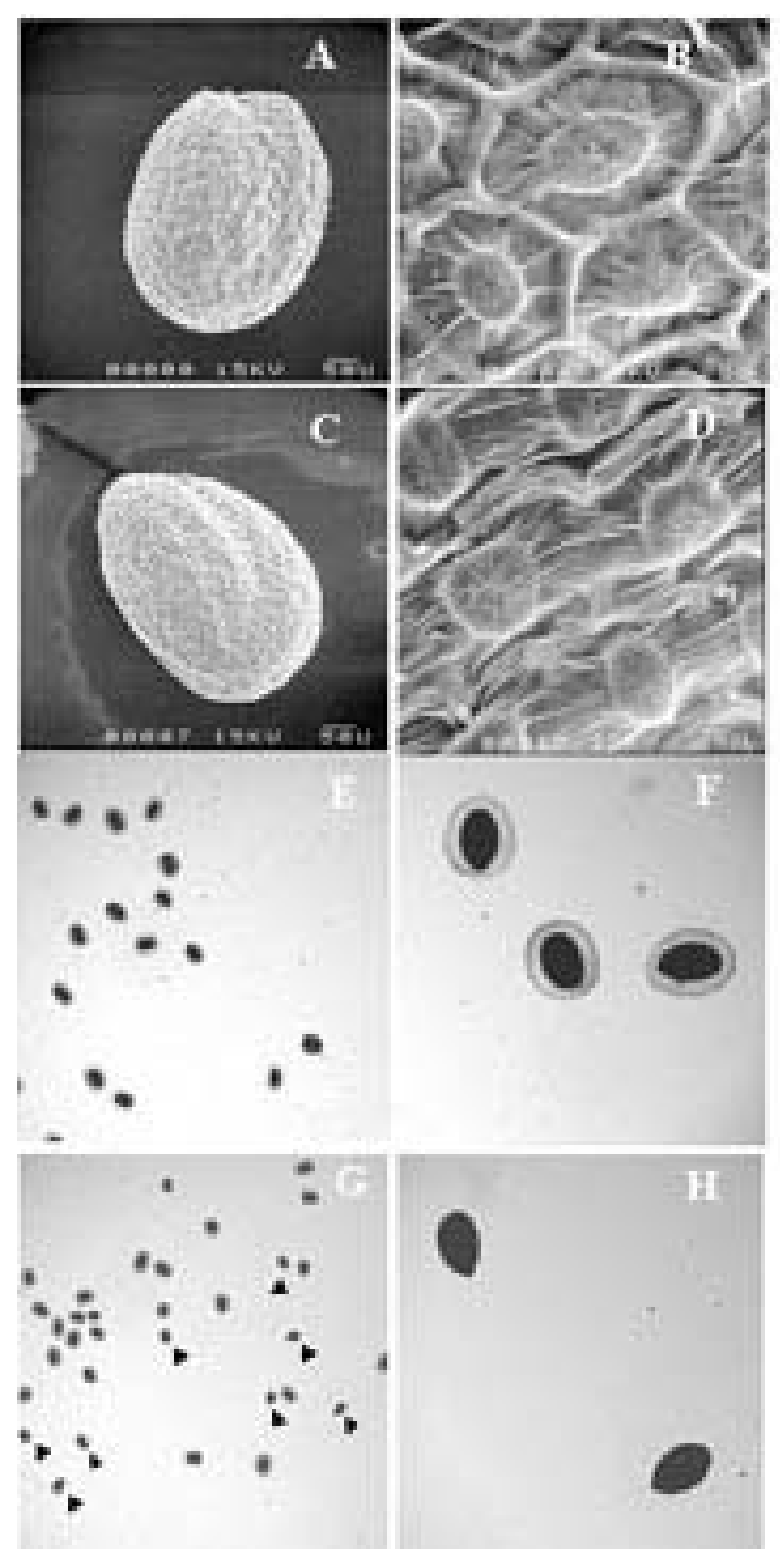

Figure 2. Scanning electron micrographs showing whole seeds $(A, C)$ and magnifications $(B, D)$ of WT $(A, B)$ and atbp80a' $(C, D)$. Ruthenium red staining of WT $(E, F)$ and seed produced by hemizygous T3 plants $(G, H)$. In $G$, arrows show seeds without ruthenium red coloration.

Scanning electron microscopy was used to compare seeds of the WT with that of the atbp80a' mutant (Fig. 2A-D). The surface of Arabidopsis WT seed consists of polygonal structure with a central elevation named columella (Fig 2A, B). Hexagonal structures were easily distinguishable by their thickened radial cell walls. However, about $1 / 4$ of the seeds produced by plants hemizygous for the T-DNA, were irregularly shaped, with thinner cell walls (Fig. 2C, D). Seeds also excrete a layer of mucilage upon imbibition and can be visualized by staining with ruthenium red. In all the WT seeds, a classical pink-stained halo is observed (Fig. 2E, F) indicating the presence of acidic pectic components (Western et al., 2000). In around $1 / 4$ of the seeds derived from plants hemizygous for the T-DNA, the ruthenium red staining was not observed (Fig. 2G, H). Collectively, these data indicated that seeds homozygous for the TDNA insertion showed alterations in seed coat structure and lacked mucilage upon imbibition compared to the WT. 
Failure to germinate may be due to various external or internal factors such as seed conservation, seed viability, dormancy or seed-coat-imposed inhibition (Koornneef et al., 2002). Since seed germination can be influenced by a large number of parameters, all the analyses were performed on several independent lines to avoid misinterpretations. Seed viability tests indicated that in all the seeds from WT and hemizygous plants, the embryo was alive and various treatments were applied to induce germination of homozygous seeds. Since $25 \%$ of seeds produced by hemizygous plants showed seed coat alterations compared to the wild type, a germination test was carried-out on seeds without seed coats. No change in germination was observed indicating that the failure to germinate was not due to seed-coat inhibition. Only a cold treatment known as stratification $\left(48 \mathrm{~h}\right.$ at $\left.4^{\circ} \mathrm{C}\right)$ induced germination of all seeds derived from hemizygous T3 plants (Fig. 3A). PCR analyses indicated the presence

A

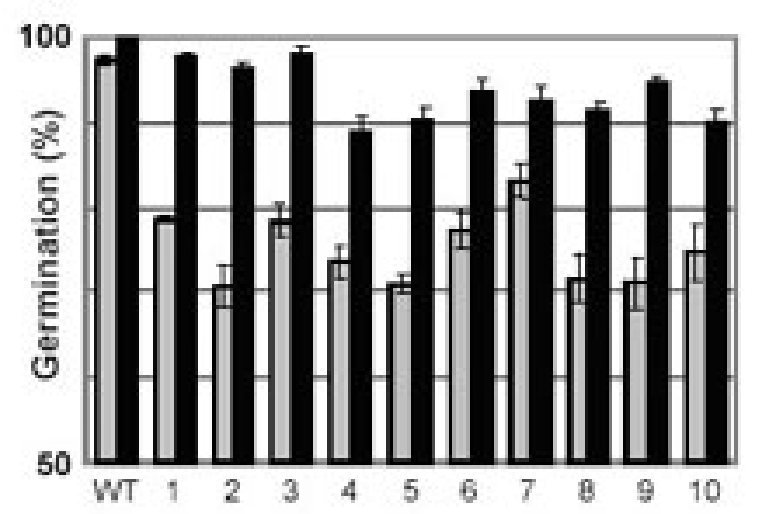

B
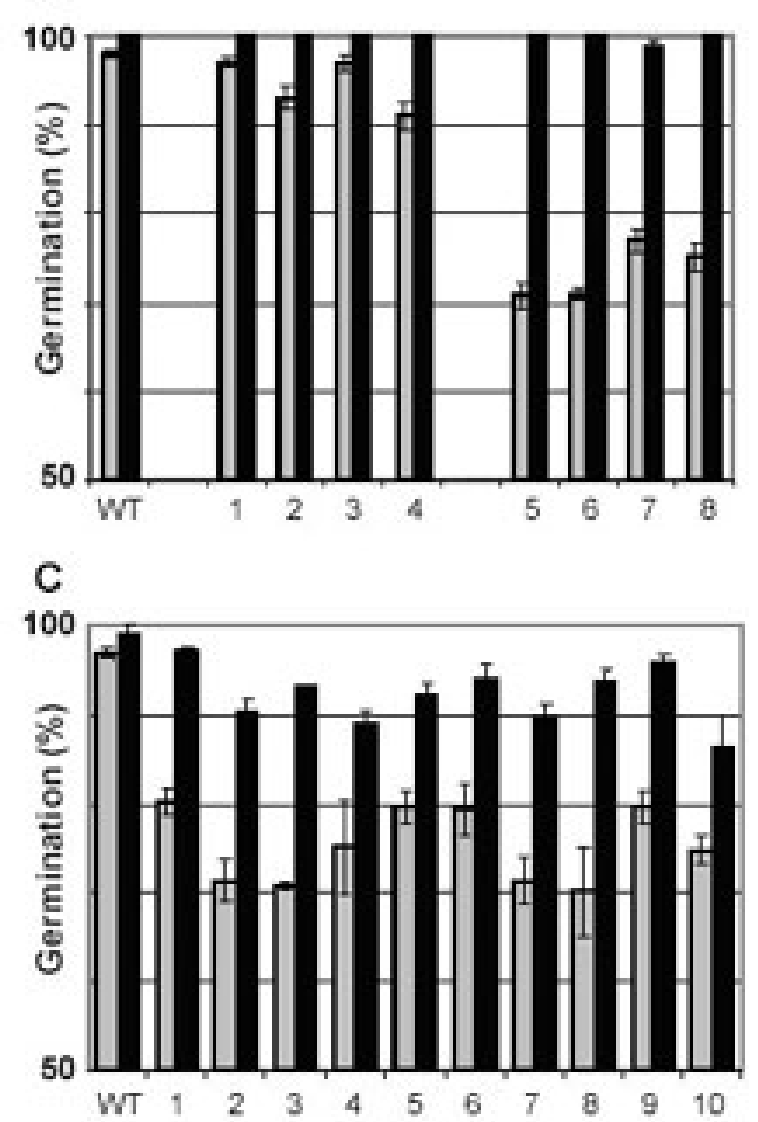

of plants homozygous for the T-DNA among the resistant plants, showing that the failure to germinate could be overcome by cold treatment. The seeds produced by plants homozygous for the T-DNA were tested for germination. Whatever the germination conditions (with or without stratification treatments), all the seed lots tested fully germinated (Fig. 3B). None of those seeds showed alteration in seed coat structure and mucilage production. In order to evaluate the heritability of this character, the germination capacity of T5 seeds, obtained from homozygous T4 plants, was assessed. T5 seeds showed the same germination level as WT.

Figure 3. Germination analyses. Germination was scored after 5 days imbibition on seeds directly placed in growth chambers at $23{ }^{\circ} \mathrm{C}$ (gray bars) or after a stratification treatment $48 \mathrm{~h}$ at $4^{\circ} \mathrm{C}$ (black bars). Results are the means of three independent experiments. (A) Effect of the stratification treatment on WT and T4 seed germination. T4 seeds were obtained from plants T3 hemizygous for the T-DNA. WT, wild type; lanes 1 to 10 correspond to T4 seeds from individual parents. $(B)$ Effect of stratification on WT and T4 seed germination. WT, wild type; lanes 1 to 4 correspond to homozygous T4 seeds, and lanes 5 to 8 to seeds produced from hemizygous T3 plants. (C) Effect of stratification on WT and F2 seeds produced after back- cross between WT and homozygous atbp80a' mutant. WT, wild type; lanes 1 to 10 correspond to $\mathrm{F} 2$ seeds from individual parents.

In conclusion, the non-germination of seeds homozygous for the T-DNA was suppressed by a cold treatment, and the ability to germinate was heritable by the following homozygous generations. Only 
homozygous seeds produced by a hemizygous parent are defective in germination. Since these observations cannot be explained by classical Mendelian genetics, the existence of an epigenetic control was assumed (Wolffe and Matzke, 1999).

\section{Germination of T-DNA homozygous seeds is linked to the T-DNA allelic state of the parental lines}

To evaluate the existence of an epigenetic control mechanism, linked to the allelic state of the plants, and to explain the reversible phenotype observed for the atbp $80 a^{\prime}$ mutant, T-DNA homozygous plants were backcrossed with WT. Hemizygous F1 plants obtained were selfpollinated and F2 seeds were harvested and tested for germination (Fig. 3C). Without stratification, about $75 \%$ of F2 seeds obtained from the backcross, germinated and $50 \%$ were $\mathrm{KAN}^{\mathrm{R}}$ as previously observed for the original hemizygous parental line. Stratification produced germination of all the F2 seeds. These data show that the non-germinating phenotype can only be observed in the absence of stratification with seeds produced by parent hemizygous for the T-DNA.

\section{The T-DNA insertion zone is highly methylated in non-germinating homozygous seeds}

In atbp $80 a^{\prime}$, the T-DNA was located $450 \mathrm{bp}$ upstream of the ATG initiation codon. According to EST available data, the T-DNA insertion occurred into the promoter region, $313 \mathrm{bp}$ upstream the initiation site of transcription. Among the mechanisms involved in epigenetic gene silencing, methylation of cytosine is a well-known DNA modification observed in plants and other eukaryotes. It provides heritable genetic mark linked to gene transcription (Bender, 2004). Mapping of methylated cytosines in the T-DNA insertion region was carried-out to estimate the degree of cytosine methylation on the region upstream of the ATG translation initiation codon of AtBP80a'. This was performed on genomic DNA prepared from WT seeds, from atbp $80 a^{\prime}$ homozygous seeds able to germinate, and from seeds produced by a hemizygous plant from the backcross experiment. In WT and the T-DNA tagged mutant homozygous seeds able to germinate, none of the cytosines present in the $650 \mathrm{bp}$ analyzed were methylated (results not shown). In contrast, for hemizygous seeds, all the cytosines of the 593 bp upstream the ATG codon in the T-DNA containing chromatids, were methylated except for four residues that presented a variable methylation state (Fig. 4).

\section{Discussion}

Results presented here show that a T-DNA insertion in the promoter region of the AtBP80a' gene in the hemizygous state blocks the germination of homozygous seeds in the progeny as well as induce alteration of seed coat. In previous work, using antisense strategy, we showed that the extinction of all the AtBP 80 genes was associated with seed germination failure (Laval et al., 2003). The atbp80a' mutant also exhibits unexpected behavior: stratification allowed complete germination of homozygous seeds, and the progeny of homozygous parents was able to germinate without cold treatment. In addition, those seeds did not show the integument and mucilage abnormalities. The mutant phenotype was only inherited when the parental lines were hemizygous for the T-DNA. These data indicate that different phenotypes can be observed for seeds having the same genotype and points to the existence of an epigenetic mechanism (Wolffe and Matzke, 1999). Homozygous seeds produced by a hemizygous parent contain heavily methylated cytosines, at symmetrical as well as nonsymmetrical positions, in the region between the T-DNA insertion and the ATG codon. In the 


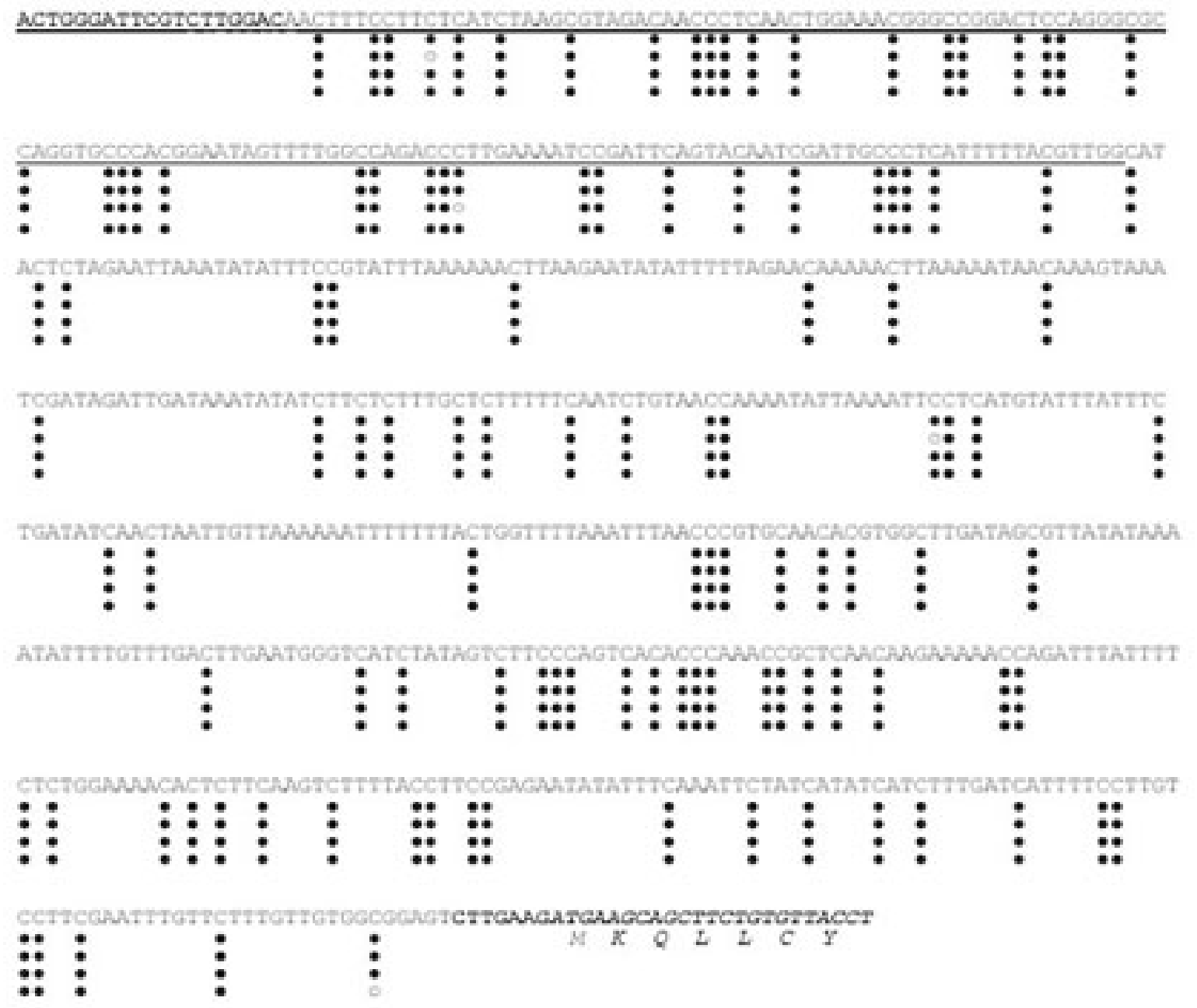

Figure 4. DNA methylation analysis of the T-DNA insertion zone in seeds produced by hemizygous plants by bisulfite sequencing. T-DNA sequence is underlined. The coding sequence and the deduced amino acid sequence of $A t B P 80 a^{\prime}$ is in italics. Sequences in bold correspond to PCR primers used. Each line shows the result of the sequencing of a different clone. Black circles indicate the methylated cytosines and empty circles indicate the non-methylated residues. Cytosine methylation was observed at symmetrical as well as non-symmetrical positions.

haploid Neurospora crassa, a gene not paired with its homologue in prophase I of meiosis forms a DNA loop, initiating Meiotic Silencing by Unpaired DNA (MSUD) (Shiu et al., 2001; Lee et al., 2004). This loop is detected and leads to a transient silencing by a posttranscriptional mechanism of all homologous sequences, including those that are themselves paired. Thus, a DNA sequence present in a single copy in any eukaryote genome could become a target for epigenetic inactivation. Epigenetic establishment may require meiosis, even if meiosis role is still unclear. The existence of such a mechanism in A. thaliana could explain the unexpected segregation data observed in the atbp80a' mutant progeny (Fig.5). At the hemizygous state, the T-DNA would be unpaired during the prophase of meiosis and constitute a target for modifications. The T-DNA and neighboring regions would then carry heritable epigenetic information. The resulting homozygous seeds would be unable to germinate because of the modifications carried on their two chromatids. In the case of homozygous plants, two T-DNAs would be paired during the prophase of meiosis and not subjected to epigenetic modifications and hence resulting homozygous seeds are able to fully germinate. We showed that the homozygous seeds are unable to germinate only when produced by a hemizygous parent, as it was corroborated by the backcross experiment where $25 \%$ of the progeny from hemizygous parent did not germinate. Similar observations were 
previously reported (Klotti et al., 2002) using transgenic rice plants carrying a betaglucuronidase reporter gene under the control of the rice tungro bacilliform virus promoter. The silencing of homozygous lines was observed when those lines were produced from hemizygous parents. The silencing was correlated with increase of methylation of the respective promoter region. This expression pattern was maintained only in homozygous lines and backcrossing experiments with non-transformed rice resulted in F1 plants with reappearance of beta-glucuronidase expression. Collectively, these data indicate that gene expression might be epigenetically controlled by DNA pairing mechanisms as previously proposed (Della Vedova and Cone, 2004; Grant-Downton and Dickinson, 2004).

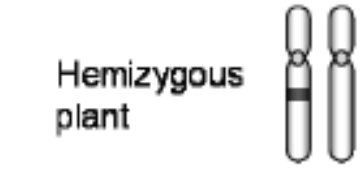

Gametogenesis

Fecondation and seed formation

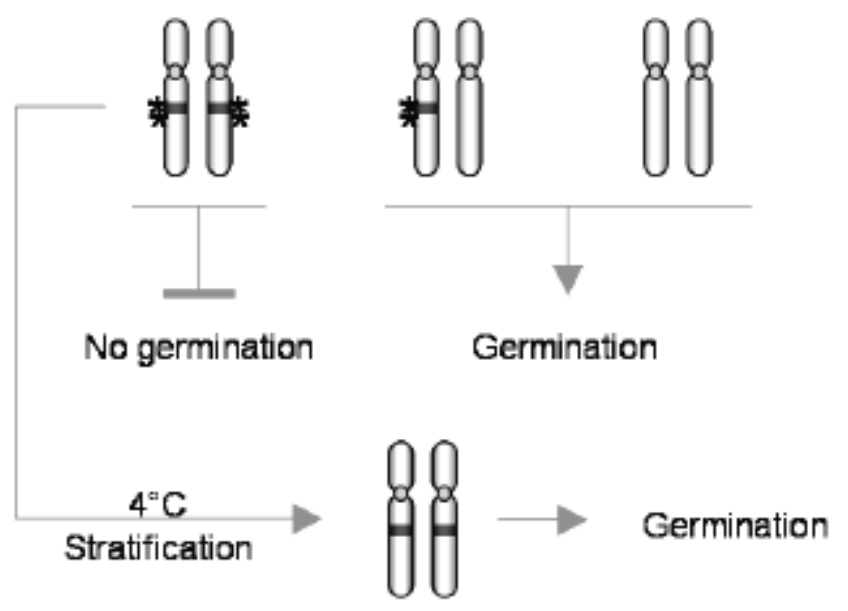

Figure 5. MSUD model in atbp $80 a^{\prime}$ T-DNA insertional mutant. In hemizygous plants, during meiosis, the T-DNA (gray) forms an unpaired DNA loop that may be responsible for cytosine methylation ( $*$ ) in the T-DNA insertion region. Two types of gametes were then produced, sharing either an epigenetic mark or not. After fecundation and seed formation, seeds having at least one WT gamete are able to germinate while those homozygous for the T-DNA cannot Stratification treatment $\left(4^{\circ} \mathrm{C}\right)$ can suppress the epigenetic mark and allow seed germination.

In the atbp80a' mutant, it would be attractive to propose that MSUD mechanisms, recently described in Neurospora, are at the origin of the observed phenomenon. In Neurospora, it was now established that gene silencing depends on post-transcriptional mechanisms and recent data using Arabidopsis T-DNA transformants

indicate that large variability in transgene expression is correlated to RNA sensing mechanisms (Schubert et al., 2004). Using systematic approach to analyze transgene expression in Arabidopsis, it was showed that difference in expression level couldn't be attributed to position effects but to post-transcriptional control of gene silencing. In our work, even if a chimeric aberrant RNA was detected by RT-PCR analysis between the T-DNA and the atbp80a' gene (data not shown), this RNA cannot be considered as the silencing signal. In such case, we would expect that this RNA acts dominantly in trans by silencing the other AtBP80 genes present in the Arabidopsis genome and all hemizygous seed produced from a hemizygous parent should not germinate. So we propose that silencing involved a cis-acting mechanism via methylation spreading in cis from the T-DNA. Similar observations were previously reported, showing that cytosine methylation can spread from the T-DNA or a foreign DNA to the host genome (Pelissier et al., 1999). It was also reported that the methylation pattern of a chromosomal region strongly influences gene activity of T-DNA by imposing DNA methylation at the borders of the integrated DNA (Pröls and Meyer, 1992). It is reasonable to propose that methylation spreading over the T-DNA into the AtBP80a' remaining promoter causes gene silencing. 
Seed stratification is commonly used to break seed dormancy and to synchronize seed germination (Bewley and Black, 1994). However, the molecular mechanisms affected by the cold treatment are still unclear. In this work, we established on one hand that T-DNA homozygous seeds unable to germinate present a high level of methylated cytosines in the promoter region of AtBP80a'. On the other hand, the T5 seeds homozygous for the T-DNA produced by cold treated T4 homozygous plants did not showed methylation in the same region. We propose that the cold phase was at the origin of demethylation in the promoter region, leading to germination. It was already demonstrated that plant-virus interactions depend on epigenetic mechanisms and that low temperature modifies gene silencing, leading to plant hypersensitivity to viruses (Szittya et al., 2003). This suggests a relationship between DNA methylation level and environmental conditions, such as cold period. We cannot exclude that in natural conditions, maintenance of seed dormancy involves epigenetic mechanisms such as DNA methylation. Similar mechanisms have proposed that a cold treatment produced an extensive DNA demethylation that was essential for flower promotion (Burn et al., 1993). In the same way, DNA de-methylation was observed during breaking of dormancy in potato bud (Law and Suttle, 2003; Horvath et al., 2003). In summary, germination of atbp80a' mutant is correlated to the presence of methylated cytosines in the promoter region inhibition of germination, and alteration of seed coat. A cold treatment probably induces DNA demethylation allowing normal seeds production and germination.

\section{Acknowledgments}

The authors are grateful to A. Jauneau and Y. Martinez (IFR40, Toulouse, France) for microscopy analyses and to E. Jamet, D. Aldon and L. Pont-Lezica for helpful discussion on the manuscript. The University Paul Sabatier (Toulouse, France) and the CNRS supported this work. F.M. was a fellow from the Ministère de l'Education Nationale, de la Recherche et de la Technologie, France.

\section{References}

Bean, C.J., Schaner, C.E. and Kelly, W.G. 2004. Meiotic pairing and imprinted X chromatin assembly in Caenorhabditis elegans. Nat Genet 36: 100-105.

Bender, J. 2004. DNA methylation and epigenetics. Annu. Rev. Plant Biol. 55: 41-68.

Bewley, J.D. and Black, M. 1994. Seeds: Physiology of Development and Germination. New York: Plenum Press.

Bourque, J.E. 1995. Antisense strategies for genetic manipulations in plants. Plant Sci 105: 125-149.

Burn, J.E., Bagnall, D.J., Metzger, J.D., Dennis, E.S. and Peacock, W.J. 1993. DNA methylation, vernalization, and the initiation of flowering. Proc Natl Acad Sci USA 90: 287-291.

Cao, X., Rogers, S.W., Butler, J., Beevers, L. and Rogers, J.C. 2000. Structural Requirements for Ligand Binding by a Probable Plant Vacuolar Sorting Receptor. Plant Cell 12: 493506.

Della Vedova, C.B. and Cone, K.C. 2004. Paramutation: the chromatin connection. Plant Cell 16: $1358-1364$.

Grant-Downton, R.T. and Dickinson, H.G. 2004. Plants, pairing and phenotypes - two's company? Trends in Genetics 20: 188-195.

Grunau, C., Clark, S.J. and Rosenthaln A. 2001. Bisulfite genomic sequencing: systematic investigation of critical experimental parameters. Nucleic Acids Res 29: E65-65. 
Horvath, D.P., Anderson, J.V., Chao, W.S. and Foley, M.E. 2003. Knowing when to grow: signals regulating bud dormancy. Trends Plant Sci 8: 534-540.

Klotti, A., He, X., Potrykus, I., Hohn, T. and Futterer, J. 2002. Tissue-specific silencing of a transgene in rice. Proc Natl Acad Sci USA 99: 10881-10886.

Koornneef, M., Bentsink, L. and Hilhorst, H. 2002. Seed dormancy and germination. Curr Opin Plant Biol 5: 33-36.

Kumpatla, S.P., Chandrasekharan, M.B., Iyer, L.M., Li, G. and Hall, T.C. 1998. Genome intruder scanning and modulation systems and transgene silencing. Trends Plant Sci 3: 97-104.

Laval, V., Masclaux, F., Serin, A., Carrière, M., Roldan, C., Devic, M., Pont-Lezica, R. and Galaud, J.P. 2003. Seed germination is blocked in Arabidopsis putative vacuolar sorting receptor (atbp80) antisense transformants. J Exp Bot 54: 213-221.

Law, R.D. and Suttle, J.C. 2003. Transient decreases in methylation at 5'-cCGG-3' sequences in potato (Solanum tuberosum L.) meristem DNA during progression of tubers through dormancy precede the resumption of sprout growth. Plant Mol Biol 51: 437-447.

Lee, D.W., Seong, K.-Y., Pratt, R.J., Baker, K. and Aramayo, R. 2004. Properties of unpaired DNA required for efficient silencing in Neurospora crassa. Genetics 167: 131-150.

Li, G., Hall, T.C. and Holmes-Davis, R. 2002. Plant chromatin: development and gene control. Bioessays 24: 234-243.

Matzke, M., Matzke, A.J. and Kooter, J.M. 2001. RNA: guiding gene silencing. Science 293: 1080-3.

Meyer, P. 2001. Chromatin remodelling. Curr Opin Plant Biol 4: 457-462.

Meyer, P. 2000. Transcriptional transgene silencing and chromatin components. Plant Mol Biol 43: 221-34.

Paszkowski, J. and Whitham, S.A. 2001. Gene silencing and DNA methylation processes. Curr Opin Plant Biol 4: 123-9.

Pelissier, T., Thalmeir, S., Kempe, D., Sanger, H.L. and Wassenegger, M. 1999. Heavy de novo methylation at symmetrical and non-symmetrical sites is a hallmark of RNAdirected DNA methylation. Nucleic Acids Res 27: 1625-1634.

Pröls, F. and Meyer, P. 1992. The methylation patterns of chromosomal integration regions influence gene activity of transferred DNA in Petunia hybrida. Plant J 2: 465-475.

Samson, F., Brunaud, V., Balzergue, S., Dubreuq, B., Lepiniec, L., Pelletier, G., Caboche, M. and Lecharny, A. 2002. FLAGdb/FST: a database of mapped flanking insertion sites (FSTs) of Arabidopsis thaliana T-DNA transformants. Nucleic Acids Res 30: 94-97.

Schubert, D., Lechtenberg, B., Forsbach, A., Gils, M., Bahadur, S. and Schmidt, R. 2004. Silencing in Arabidopsis T-DNA transformants : the predominant role of a gene-specific RNA sensing mechanism versus position effects. Plant Cell 16: 2561-2572.

Shiu, P.K., Raju, N.B., Zickler, B. and Metzenberg, R.L. 2001. Meiotic silencing by unpaired DNA. Cell 107: 905-916.

Shiu, P.K. and Metzenberg, R.L. 2002. Meiotic silencing by unpaired DNA: properties, regulation and suppression. Genetics 161: 1483-1495.

Szittya, G., Silhavy, D., Molnar, A., Havelda, Z., Lovas, A., Lakatos, L., Banfalvi, Z. and Burgyan, J. 2003. Low temperature inhibits RNA silencing-mediated defence by the control of siRNA generation. EMBO J 22: 633-640.

Vaucheret, H. 1993. Identification of a general silencer for $19 \mathrm{~S}$ and $35 \mathrm{~S}$ promoters in a transgenic tobacco plant: $90 \mathrm{pb}$ of homology in the promoter sequences are sufficient for trans-inactivation. C R Acad Sci Paris 316: 1471-1483.

Verbsky, M.L. and Richards, E.J. 2001. Chromatin remodeling in plants Curr Opin Plant Biol 4: 494-500 
Wassenegger, M., Heimes, S., Riedel, L. and Sanger, H.L. 1994. RNA-directed de novo methylation of genomic sequences in plants. Cell 76: 567-576.

Western, T.L., Skinner, D.J. and Haughn, G.N. 2000. Isolation and characterization of mutants defective in seed coat mucilage secretory cell development in Arabidopsis. Plant Physiol 122: 345-355.

Wolffe, A.P. and Matzke, M.A. 1999. Epigenetics: regulation through repression. Science 286: 481-486. 